\title{
Recurrent Giant Phyllodes Tumour of the Breast Pathological Considerations and Management Approach for Recurrence and Metastasis ${ }^{*}$
}

\author{
Norman Oneil Machado \\ Department of Surgery, Sultan Qaboos University Hospital, Muscat, Oman \\ Email: oneilnorman@gmail.com
}

Received October 28, 2011; revised March 6, 2012; accepted March 22, 2012

\begin{abstract}
Phyllodes tumours are rare and account for $0.4 \%$ of all breast tumours. The majority of them tend to be less than $5 \mathrm{cms}$ in size with giant tumours larger than $10 \mathrm{cms}$ being about $20 \%$ of these cases. They display a broad range of clinical and pathological behavior and are regarded as falling within the spectrum of fibroepithelial neoplasms. Surgery has been the primary modality of treatment. However the extent of resection and the role of adjuvant radiotherapy and chemotherapy are still controversial. The risk of recurrence is $(4.7 \%-30 \%)$ for benign phyllodes tumour and $(30 \%-65 \%)$ for borderline and malignant phyllodes tumour. A case of giant phyllodes tumour measuring $36 \times 30 \mathrm{~cm}$ and weighing $6.8 \mathrm{~kg}$ is presented, which had recurred following a previous resection 5 years back. The literature is reviewed with regards to pathology, the role of investigations, nature of resection and the risk factors for recurrence and metastasis
\end{abstract}

Keywords: Phyllodes Tumour, Mastectomy, Giant Tumour, Recurrence

\section{Introduction}

Phylloides tumour (PT) are rare fibroepithelial breast tumours that usually occur in adults and are usually seen in women aged 35 to 55 years with only a few cases reported in men [1-4]. They are composed of benign epithelial component and a cellular spindle cell stroma forming a leaf like structure [1-5]. No one morphology is reliable in predicting the clinical behavior of the tumour. While the surgical management of phylloides tumour has been addressed many times in the literature controversy still exist [1-9]. There are only a few reports however that has specifically commented on giant phyllodes tumour as an entity, which presents to the surgeon with general unique management problem [6]. The median size of the tumour is around 4 to $7 \mathrm{~cm} \mathrm{[1-8].} \mathrm{Twenty} \mathrm{per}$ cent of tumours grow larger than $10 \mathrm{~cm}$, the arbitrary cut off point for the defining giant tumours [1-8]. While presenting one of the large giant phyllodes tumour reported in the English literature, the literature is also reviewed with regards to its pathology, management and risk factors for recurrence and metastasis

\section{Case Report}

A 62-year-old lady presented with large right breast lump

*Disclosure: There is no conflict of interest and there is no financial assistance from any source. of 14 months duration. This was associated with breast pain. The lump was measuring $36 \times 32 \mathrm{~cm}$ with an overlying scar of previous surgery being apparent (Figures 1 and 2). The lump was firm and mobile and there were no axillary lympadenopathy. Five years back she had undergone wide excision of a breast lump measuring $3 \times 4$ $\mathrm{cm}$ in another hospital, which was reported as benign PT with clear resected margin. A CT scan of the present breast lump revealed a large well-circumscribed lobulated mass involving the whole breast with stretching of the overlying skin. A CT scan of the abdomen and chest

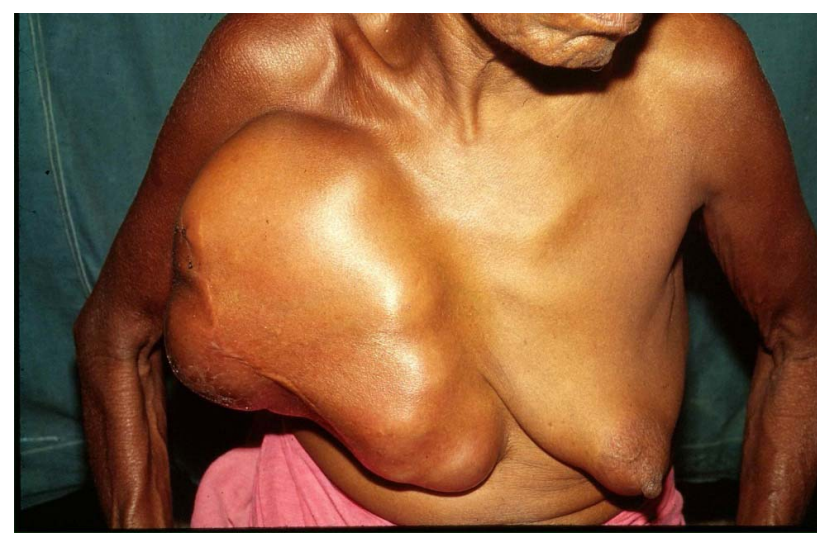

Figure 1. A large phyllodes tumour involving the whole right breast. The scar of previous surgery is seen. 
however revealed no metastasis. A core biopsy of the lesion confirmed borderline phyllodes tumour. She underwent mastectomy without reconstructive surgery. The histopathology report confirmed borderline phyllodes tumour (Figure 3) with tumour free resected margins. When last followed up 5 years later she was doing well with no recurrence.

\section{Discussion}

PT are fibroepithelial neoplasms with epithelial and cellular stromal components, the latter of which represents the neoplastic process [4,5]. The presence of an epithelial component differentiates PT from other stromal tumours [3-5]. They make up to $0.3 \%$ to $0.5 \%$ of the female breast tumours and have an incidence of about 2.1 per million, the peak of which occur in women aged 45 to 49 years, 15 to 20 years later than that for fibroadenoma [18]. The tumour is rarely found in adolescent and elderly. PT usually presents as a rapidly growing but clinically benign breast lump. In some patients, a lump may be

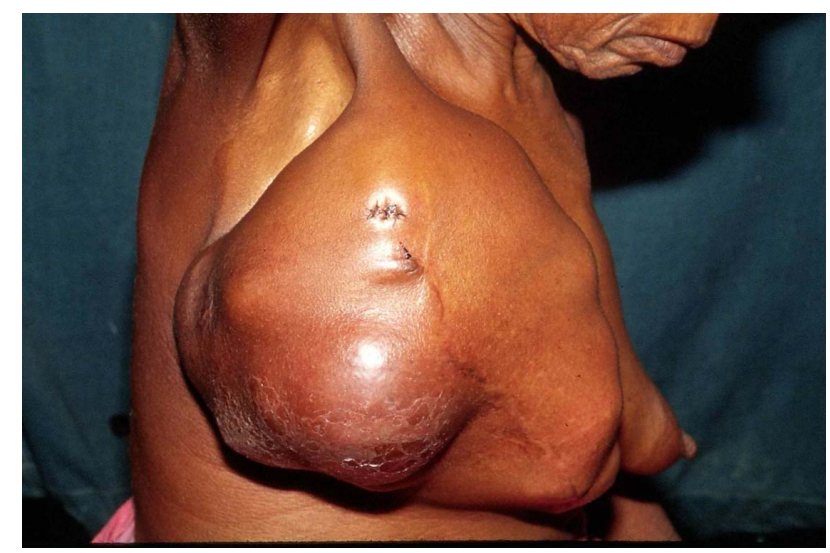

Figure 2. The large phyllodes tumour revealing the stretched overlying skin in the lower quadrant.

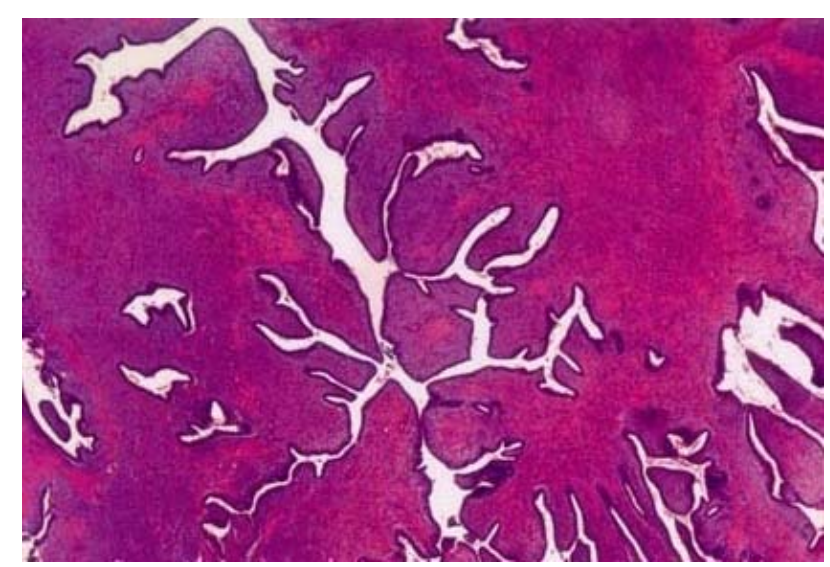

Figure 3. Histopathology of resected specimen revealing borderline phyllodes tumour with pushing margin and stromal atypia. apparent for several years, but they only come for evaluation when the mass has suddenly increased in size. Delay between the first symptom and presentation can vary from 2 days to 15 years and a breast lump is noted in $74 \%$ of these patients [4]. The other symptoms include mastodynia (14\% to $42 \%)$ and less frequently skin ulceration (2.4\% to $10 \%)$ of the cases, which are usually associated with large or malignant PT [4,7]. Due to the large size of the tumour the overlying skin is tense and presents with visible and dilated venous plexus that may eventually ulcerate [1]. The tumour size is reported to vary from 5 to $450 \mathrm{~mm}$ with a mean size of 40 to $70 \mathrm{~mm}$ [1-8]. PT is unilateral in $96 \%$ of cases with very few cases of bilaterality reported $[3,4]$ They are commonly found in upper quadrant (46\%) with an equal propensity to occur in either breast (48.8\% to $50 \%$ ) $[3,8]$.

PT can be extremely difficult to differentiate from fibroadenoma, which is sometimes treated with a nonoperative approach. For this reason, early diagnosis of PT, which often includes surgery, is pursued [1-4]. The preoperative diagnosis is reported to be achieved in 10 to $29 \%$ of cases using various diagnostic modalities [9]. Ultrasound examination of the breast has distinct advantage as an initial investigation in view of its ease of performing and availability. Various diagnostic features, which are characteristic, include a well-circumscribed lobulated mass, heterogeneous internal echo pattern and lack of microcalcification $[4,10]$. Patients with fibroadenoma are generally younger than patients with PT and have a larger ratio of length to anteroposterior diameter and are generally smaller in size than PT [10]. Attempt to establish a preoperative diagnosis and to differentiate between malignant and benign PT through the use of colour Doppler ultrasound has been made [11]. The feature that is suggestive of malignancy includes marked hypoechogenicity, posterior acoustic shadowing and higher vmax (systolic peak flow velocity) [11]. Mammography however is reported to be extremely low in accuracy in differentiating a PT and fibroadenoma. However, in tumours which are large, presence of irregular margin are more likely to be predictive of malignant PT rather than benign PT. MRI has also played a significant role in diagnosing difficult cases. The feature characterizing benign PT included a lobulated or polygonal shaped mass with smooth border, which may be cystic and septated and has a gradual or rapid pattern of time signal intensity curve [12]. The reported pathognomic feature of PT also include characteristic leafy internal morphology, best shown in subtraction MRI which highlights the enhancing cotyledons solid pattern within irregular blood filled cystic spaces [12].

Preoperative histological diagnosis can be achieved by fine needle aspiration (FNA) or core biopsy [10-13]. The role of FNA in establishing a preoperative diagnosis is 
limited with reported success of around $12 \%$, the limiting factor being the common cytological feature with fibroadenoma (FA). However, the presence of elongated spindle cells in the background is reported more likely to be present in PT, than FA [13]. Core biopsy is preferred for establishing a preoperative diagnosis, as the histological gain from this procedure is important in guiding surgical treatment. Most of the PT is benign with $15 \%$ to $30 \%$ being classified as malignant [1-8]. PT is generally divided into benign, borderline and malignant histotype based on the macroscopic appearance of the stromal component [3-5]. A benign tumour is characterized by 0 - 4 mitosis/10 high power field (HPF), predominately pushing margin, and usually $1+$ but occasionally 2+ stromal atypia. Borderline tumour are determined by 5 9 mitosis/10 HPF, pushing or infiltrating margin, and 2+ stromal atypia and malignant PT is characterized by 10 or more mitosis/10 HPF, predominately infiltrating margin usually 3+ but occasionally 2+ stromal atypia [3-5]. Histological appearance may not however correlate with clinical behavior as both malignant and borderline tumour has been shown to be capable of metastasizing. Histotype however is reported to be an independent prognostic factor with 5 year survival of $95.7 \%$ for benign tumours, $73.7 \%$ for borderline and $66 \%$ for malignant tumours $[1-4,7,8]$. The 10-year survival drops to $79 \%$ for benign and $42 \%$ for malignant tumours $[1-4,7,8$, 14-16]. Metastasis has been noted in $25 \%$ to $31 \%$ of malignant PT but in only 4\% of all PT [1-4]. The most common sites of metastasis include lungs; bone liver and distant lymph nodes [1-5,14-16]. Skin involvement with tumour does not appear to be a predictor of metastasis. About $20 \%$ of patients have palpable axillary lymphnodes on presentation but only $5 \%$ of these show histological evidence of metastasis upon pathological examination [1-5,14-18]. Among the malignant PT only 15\% metastasize to axilla [1-4]. The metastatic lesion contains only stromal elements with no malignant epithelial elements observed. In view of the rarity of lymph nodal involvement most of the authors are of the view that routine removal of lymph nodes is not necessary unless they are palpable [1-4].

About $20 \%$ of PT is considered giant when the size exceeds $10 \mathrm{~cm}$ in diameter [5,14-18]. However the importance of this cut off value has been disputed as there is a continuing debate over the prognostic significance of the tumour size [1,2]. Even though malignant tumours tend to be larger than benign, the malignant histotype correlating with size has not been well established $[1,2]$. Various factors have been found to be related to clinical behavior and outcome. Of these stromal overgrowth, tumour necrosis and mitotic activity have been found to be the most consistently associated with recurrence, metastasis and poor survival $[2,14,15]$. Other factors that may correlate with outcome are tumour size $[2,3,15,16]$, stromal atypia [14] and stromal cellularity [17], lymph node metastasis [16], age [2,16], nulliparity and absence of cysts.

Local recurrence usually occurs within few years after the surgery and histologically resembles the original tumor [1-6] [Table 1]. Occasionally recurrent tumour shows increased cellularity and more aggressive histological features than the original lesion [2-6]. This was evident in our case where an initially benign tumour recurred as borderline malignant tumour. In most patients local recurrence is isolated and is not associated with development of distant metastasis [1-4,14-17]. Among these various pathological factors, mitotic activity and inadequate margin clearance following resection was strongly associated with recurrence while stromal cellularity, stromal overgrowth, stromal atypia, along with mitotic activity, tumour margin positivity and heterologous stromal elements significantly correlated with metastasis [3]. All PT can recur regardless of their histotype although the risk of recurrence is low in benign form, ranging from $4.7 \%$ to $30 \%$, and notably higher in borderline and malignant form (30\% to 65\%) [1-5,14-16]. However review of literature of recent publications revealed that local recurrence after margin negative breast conserving resection of borderline malignant and malignant PT was found to be $21.7 \%$ and $16 \%$ respectively [3,4,19-31] (Table 1) Local recurrence can usually be controlled by further wide excision and mastectomy is invariably not required. Mastectomy is however considered for local recurrence after local surgery has been performed for borderline or malignant tumour [1,2]. Occasionally aggressive local recurrence can result in widespread chest wall invasion with direct invasion of the underlying lung parenchyma. Isolated reports of good palliation in this situation with radiotherapy have been reported [1].

Surgery is the treatment of choice for PT, but the extent of surgery remains controversial particularly for borderline and malignant PT [1-8,14-17]. Most authors agree that the appropriate procedure for benign PT is a wide local excision allowing 1 to $2 \mathrm{~cm}$ margin in all directions [1-8,14-18]; however enulceation alone is considered insufficient [15,17]. In the event, the diagnosis of benign PT is a histological surprise following excision of breast lump, re-exploration with wider resection of healthy tissue is not considered justified because of the low recurrence rate [2-4]. While these patients may enter into a surveillance programme, patients with histologically positive resection margin should undergo further surgery [2-4,8]. However in malignant PT and tumours larger than $5 \mathrm{cms}$, mastectomy is often recommended [24,14-16]. Routine resection of the axillary lymph node is not recommended as metastasis is seen in only in around $5 \%$ to $10 \%[1-4,6-8,14-17]$. The role of adjuvant radio- 
Table 1. Review of literature-local recurrence after margin negative breast conserving resection of borderline malignant and malignant phyllodes tumours.

\begin{tabular}{|c|c|c|c|c|c|c|}
\hline Study & Year & $\begin{array}{c}\text { No of local } \\
\text { Recurrence Borderline }\end{array}$ & $\begin{array}{c}\text { Total patients } \\
\text { Malignant }\end{array}$ & Total & $\begin{array}{l}\text { Median follow } \\
\text { up (y) }\end{array}$ & $\begin{array}{l}\text { Median time to } \\
\text { recurrence (month) }\end{array}$ \\
\hline Lenhard et al. [19] & 2007 & $2 / 10$ & $2 / 6$ & $4 / 16$ & 7.1 & 72 \\
\hline Barrio et al. [20] & 2007 & - & $5 / 40$ & $5 / 40$ & 8.3 & 24 \\
\hline Taira et al. [21] & 2007 & $0 / 5$ & $1 / 6$ & $1 / 11$ & 8.2 & 18 \\
\hline Abdalla et al. [22] & 2006 & $4 / 11$ & $2 / 5$ & $6 / 16$ & 5 & ND \\
\hline Fou et al. [23] & 2006 & - & $4 / 17$ & $4 / 17$ & 4.3 & 14 \\
\hline Ben hassouna J et al. [4] & 2006 & $5 / 16$ & $5 / 28$ & $10 / 44$ & 3.7 & \\
\hline Chen WH [3] & 2005 & $0 / 12$ & $0 / 29$ & $0 / 41$ & 5.91 & \\
\hline Asoglu et al. [31] & 2004 & $2 / 3$ & $6 / 19$ & $8 / 22$ & 7.5 & 17 \\
\hline Kok et al. [24] & 2001 & $1 / 3$ & $1 / 1$ & $2 / 4$ & 3.1 & 8 \\
\hline Kapiris et al. [25] & 2001 & - & $4 / 14$ & $4 / 14$ & 9 & 10 \\
\hline Chaney et al. [26] & 2000 & - & $0 / 6$ & $0 / 6$ & 4 & - \\
\hline Holthouse et al. [27] & 1999 & $0 / 2$ & $0 / 2$ & $0 / 4$ & 10 & - \\
\hline Zissis et al. [28] & 1998 & - & $0 / 3$ & $0 / 3$ & 6.6 & - \\
\hline de Roos et al. [29] & 1998 & $0 / 1$ & $0 / 1$ & $0 / 2$ & NR & - \\
\hline Reinfuss et al. [30] & 1996 & $3 / 15$ & $0 / 4$ & $3 / 19$ & 8 & $<20$ \\
\hline Total (\%) & & $17 / 78(21.7 \%)$ & $30 / 180$ (16.6\%) & 47/258 (18.2\%) & & \\
\hline
\end{tabular}

therapy or chemotherapy remains uncertain [8]. Some investigators report that radiotherapy improves disease free survival [32,33]. A significant reduction in local recurrence has been reported when margin negative resection has been combined with adjuvant radiotherapy; Adjuvant radiotherapy following margin negative resection of borderline and malignant PT, lead to reduction of recurrence from $86 \%$ without adjuvant radiotherapy to $59 \%$ when radiotherapy was used $(p=0.02)$ [33]. There are others who recommend adjuvant radiotherapy only in cases of incomplete resection [8,32]. Chemotherapy may be considered in patients with stromal overgrowth [15]. However to date neither adjuvant radiotherapy or chemotherapy are routinely recommended [1-4].

\section{Conclusion}

PT represents a heterogeneous group of tumours sharing the same macroscopic features with an unpredictable outcome. The prognosis depends on the histological and biological characteristics of the tumour rather than their clinical behavior. Giant PT constitutes $20 \%$ of these tumours and would invariably need mastectomy. The data concerning the prognostic factors of PT are conflicting and both benign and malignant PT could recur or metastasize. While ultrasound, CT and MRI of the breast could be suggestive of PT, establishing a definite preoperative diagnosis may be difficult and would invariably need core biopsy. Surgery remains the cornerstone of treatment consisting of resection with healthy surrounding breast tissue at initial surgery. Local recurrence can be controlled with further surgery and may not be associated with distant metastasis. Routine axillary lymph node dissection is not recommended. High risk of local recurrence and or metastasis is usually associated in patients with large tumours, infiltrating tumour margin, severe stromal overgrowth, atypia and cellularity.

\section{REFERENCES}

[1] S. J. Parker and S. A. Harries, "Phyllodes Tumours," Postgraduate Medical Journal, Vol. 77, No. 909, 2001, pp. 428-435. doi:10.1136/pmj.77.909.428

[2] M. Pandey, A. Mathew, J. Kattor, E. K. Abraham, B. S. Mathew, B. Rajan and K. M. Nair, "Malignant Phyllodes Tumours,” Breast Journal, Vol. 7, No. 6, 2001, pp. 411416. doi:10.1046/j.1524-4741.2001.07606.X

[3] W. H. Chen, S. P. Cheng, C. Y. Tzen, T. L. Yang, K. S. Jeng, C. L. Liu and T. P. Liu, "Surgical Treatment of Phyllodes Tumours of the Breast. Retrospective Review of 172 Cases,” Journal of Surgical Oncology, Vol. 91, No. 3, 2005, pp. 185-194.

[4] J. Ben Hassouna, T. Damak, A. Gamoudi, R. Chargui, F. Khomsi, S. Mahjoub, et al., "Phyllodes Tumours of the Breast: A Case Series of 106 Patients,” American Journal of Surgery, Vol. 192, No. 2, 2006, pp. 141-147. doi:10.1016/j.amjsurg.2006.04.007

[5] M. Pietruszka and L. Barnes, "Cystosarcoma Phyllodes. A Clinicopathologic Analysis of 42 Cases," Cancer, Vol. 41, No. 5, 1978, pp. 1974-1983. doi:10.1002/1097-0142(197805)41:5<1974::AID-CNCR2 


\section{3>3.0.CO;2-C}

[6] C. Walravens and C. De Greef, "Giant Phyllodes tumour of the Breast," Journal of Plastic, Reconstructive \& Aesthetic Surgery, Vol. 61, No. 10, 2008, pp. e9-e11. doi:10.1016/j.bjps.2007.10.018

[7] N. Matar, A. Soumani, M. Noun, T. Chraibi, A. Himmi, A. El Mansouri, et al., "Phyllodes Tumour of the Breast. Forty One Cases,” Journal de Gynécologie, Obstétrique et Biologie de la Reproduction, Vol. 26, No. 1, 1997, pp. 32-36.

[8] J. F. Stebbing and A. G. Nash, "Diagnosis and Management of Phyllodes Tumour of the Breast: Experience of 33 Cases at a Specialist Center," Annals of the Royal College of Surgeons of England, Vol. 77, No. 3, 1995, pp. 181-184.

[9] L. M. Foxcroft, E. B. Evans and A. J. Porter, "Difficulties in the Pre-Operative Diagnosis of Phyllodes Tumour of the Breast: A Study of 84 Cases,” Breast, Vol. 16, No. 1, 2007, pp. 27-37. doi:10.1016/j.breast.2006.05.004

[10] M. K. Bode, T. Rissanen and M. Apaja-Sarikkinen, "Ultrasonography and Core Needle Biopsy in the Differential Diagnosis of Fibroadenoma and Tumour Phyllodes," Acta Radiologica, Vol. 48, No. 7, 2007, pp. 708-713. doi:10.1080/02841850701367911

[11] P. De Albertis, M. Oliveri, P. Quadri, G. Serafini, A. Cavallo, O. Orlando, et al., "Retrospective Analysis of Color Doppler Ultrasonography and Flowmetry Findings in Solid Nodular Pathology of the Breast," Radiology Medicine, Vol. 89, No. 1-2, 1995, pp. 28-35.

[12] M. Takahashi, K. Murata, M. Mori, N. Kawaguchi, A. Furukawa, R. Kushima and R. Morita, "Giant Metastatic Cystosarcoma Phyllodes to the Lung: CT and MR Findings,” Radiation Medicine, Vol. 10, No. 5, 1992, pp. 210213.

[13] S. Krishnamurthy, R. Ashfaq, H. J. Shin and N. Sneige, "Distinction of Phyllodes Tumour from Fibroadenoma: A Reappraisal of an Old Problem,” Cancer, Vol. 90, No. 6, 2000, pp. 342-349. doi:10.1002/1097-0142(20001225)90:6<342::AID-CNCR 4>3.0.CO;2-I

[14] G. Cohn-Cedermark, L. E. Rutqvist, I. Rosendahl and C. Silfversward, "Prognostic Factors in Cystosarcoma Phyllodes. A Clinicopathological Study of 77 Patients," Cancer, Vol. 68, No. 9, 1991, pp. 2017-2022. doi:10.1002/1097-0142(19911101)68:9<2017::AID-CNC R2820680929>3.0.CO;2-V

[15] A. W. Chaney, A. Pollack, M. D. McNeese, G. K. Zagars, P. W. Pisters, R. E. Pollock, et al., "Primary Treatment of Cystosarcoma Phyllodes of the Breast," Cancer, Vol. 89, No. 7, 2000, pp. 1502-1511. doi:10.1002/1097-0142(20001001)89:7<1502::AID-CNC R13>3.0.CO;2-P

[16] H. J. Norris and H. B. Taylor, "Relationship of Histologic Features to Behavior of Cystosarcoma Phyllodes, Analysis of Ninety-Four Cases," Cancer, Vol. 20, No. 12, 1967, pp. 2090-2099. doi:10.1002/1097-0142(196712)20:12<2090::AID-CNCR 2820201206>3.0.CO;2-L

[17] B. Salvadori, F. Cusumano, R. Del Bo, V. Delledonne, M.
Grassi, D. Rovini, et al., "Surgical Treatment of Phyllodes Tumour of the Breast,” Cancer, Vol. 63, No. 12, 1989, pp. 2532-2536.

doi:10.1002/1097-0142(19890615)63:12<2532::AID-CN CR2820631229>3.0.CO;2-Q

[18] R. W. McDivitt, J. A. Urban and J. H. Farrow, "Cystosarcoma Phyllodes,” Johns Hopkins Medical Journal, Vol. 120, No. 1, 1967, pp. 33-45.

[19] M. Lenhard, S. Kahlert, I. Himsi, et al., "Phyllodes Tumour of the Breast: Clinical Follow-Up of 33 Cases of This Rare Disease," European Journal of Obstetrics \& Gynecology and Reproductive Biology, Vol. 138, No. 2, 2007, pp. 217-221. doi:10.1016/j.ejogrb.2007.08.002

[20] A. Barrio, B. Clark, J. Goldberg, et al., "Clinicopathologic Features and Long Term Outcomes of 293 Phyllodes Tumour of the Breast," Annals of Surgical Oncology, Vol. 14, No. 10, 2007, pp. 2961-2970. doi:10.1245/s10434-007-9439-z

[21] N. Taira, D. Takabatake, K. Aogi, et al., "Phyllodes Tumour of the Breast: Stromal Overgrowth and Histological Classification Are Useful Prognosis-Predictive Factors for Local Recurrence in Patients with a Positive Surgical Margin,” Japanese Journal of Clinical Oncology, Vol. 37, No. 10, 2007, pp. 730-736. doi:10.1093/jjco/hym099

[22] H. Abdalla and M. Sakr, "Predictive Factors of Local Recurrence and Survival Following Primary Surgical Treatment of Phyllodes Tumour of the Breast," Journal of the Egyptian National Cancer Institute, Vol. 18, No. 2, 2006, pp. 125-133.

[23] A. Fou, F. Schnabel, D. Hamele-Bena, et al., "Long Term Outcomes of Malignant Phyllodes Tumours Patients: An Institutional Experience," American Journal of Surgery, Vol. 192, No. 4, 2006, pp. 492-495. doi:10.1016/j.amjsurg.2006.06.017

[24] K. Kok, P. Telesinghe and S. Yapp, “Treatment and Outcome of Cystosarcoma Phyllodes in Brunei: A 13 Year Experience," Journal of the Royal College of Surgeons of Edinburgh, Vol. 46, No. 4, 2001, pp. 198-201.

[25] I. Kapiris, N. Nasir, R. A’hern, V. Healy and G. Gui, "outcome and Predictive Factors of Local Recurrence and Distant Metastasis Following Primary Surgical Treatment of High Grade Malignant Phyllodes Tumours of the Breast,” European Journal of Surgical Oncology, Vol. 27, No. 5, 2001, pp. 723-730. doi:10.1053/ejso.2001.1207

[26] A. Chaney, A. Pollack, M. McNeese, et al., "Primary Treatment of Cyst Sarcoma Phloxes of the Breast," Cancer, Vol. 89, No. 7, 2000, pp. 1502-1511. doi:10.1002/1097-0142(20001001)89:7<1502::AID-CNC R13>3.0.CO;2-P

[27] D. Holthouse, P. Smith, R. Naunton-Morgon and D. Minchin, "Cystosarcoma Phyllodes: The Western Australian Experience,” Australian and New Zealand Journal of Surgery, Vol. 69, No. 9, 1999, pp. 635-638. doi:10.1046/j.1440-1622.1999.01654.x

[28] C. Zissis, N. Apostolikas, A. Konstantinidou, J. Griniatsos and P. Vassilopoulas, "The Extent of Surgery and Prognosis of Patients with Phyllodes Tumour of the Breast," Breast Cancer Research and Treatment, Vol. 48, No. 3, 1998, pp. 205-210. 
doi:10.1023/A:1005980831359

[29] W. de Roos, P. Kaye and D. Dent, "Factors Leading to Local Recurrence or Death after Surgical Resection of Phyllodes Tumours of the Breast," British Journal of Surgery, Vol. 86, No. 3, 1999, pp. 396-399. doi:10.1046/j.1365-2168.1999.01035.x

[30] M. Reinfuss, J. Mitus, K. Duda, et al., "The Treatment and Prognosis of Patients with Phyllodes Tumour of the Breast,” Cancer, Vol. 77, 1996, pp. 910-916.

[31] O. Asoglu, M. Ugurlu, K. Blanchard, et al., "Risk Factors for Recurrence and Death after Primary Surgical Treatment of Malignant Phyllodes Tumours," Annals of Surgical Oncology, Vol. 11, No. 11, 2004, pp. 1011-1017.
doi:10.1245/ASO.2004.02.001

[32] R. Soumarova, Z. Seneklova, H. Horova, H. Vojkovska, I. Horova, M. Budikova, J. Ruzickova and B. Jezkova, "Retrospective Analysis of 25 Women with Malignant Cystosarcoma Phyllodes-Treatment Results,” Archives of Gynecology and Obstetrics, Vol. 269, No. 4, 2004, pp. 278-281. doi:10.1007/s00404-003-0593-7

[33] R. J. Barth, W. A. Wells, S. E. Mitchell and B. F. Cole, "A Prospective Multi-Institutional Study of Adjuvant Radiotherapy after Resection of Malignant Phyllodes Tumours,” Annals of Surgical Oncology, Vol. 16, No. 8, 2009, pp. 2288-2294. doi:10.1245/s10434-009-0489-2 